Tạp chí Khoa học và Công nghệ biển T11 (2011). Số 1. Tr 73 - 83

\title{
BƯớC ĐÀU SO SÁNH HIỆU QUẢ CỦA VIỆC SỬ DỤNG LƯỡI CÂU VòNG VÀ LƯỡI CÂU THƯờNG TRONG KHAI THÁC NGUÔN LỢI CÁ NỔI Ở BIỄN VIỆT NAM
}

\author{
VŨ VIỆT HÀ, NGUYẼ̃N VĂN HẢI \\ Viện Nghiên cứu Hải sản
}

\begin{abstract}
Tóm tắt: Trong hai năm 2009 và 2010, tổng số 14 chuyến biển sủ dụng tàu câu vàng thử nghiệm sử dụng đồng thời luỡi câu thường và lữ̛i câu vòng khai thác cá nổi lớn ở vùng biển xa bò miền Trung và Đông Nam đã đurợc thực hiện. Mục đích của thí nghiệm là xác định hiệu quả khai thác của luõi câu vòng so với luỡi câu thwờng đồng thời đánh giá khả năng giảm thiểu sụ mắc câu của rùa biển. Kết quả nghiên cứu cho thấy, năng suất khai thác của luỡi câu vòng và luõ̃i câu thuờng không khác nhau, tuy nhiên thành phần sản luợng khai thác thì khác nhau giữa hai loại luõ̃i câu. Luỡi câu vòng khai thác hiệu quả hơn đối với cá ngù̀ vây vàng và các loài cá nhám, cá cờ. Ngược lại, năng suất khai thác của luõ̃i câu thuờng đối với cá ngù mắt to cao hơn. Kết quả nghiên cứu cũng buớc đầu cho thấy, khả năng giảm thiểu sụ mắc câu của rùa biển đối với lươi vòng cao hơn so với luỡi câu thường.
\end{abstract}

Từ khóa: Luõ̃i câu vòng, luõ̃i câu thuoòng, cá nổi lớn, năng suất khai thác, thành phần loài

\section{MỞ ĐÀ̀}

Từ những năm 90 của thế kỷ trước, nghề câu vàng khai thác cá ngừ Đại dương đã bắt đầu phát triển ở Việt Nam. Sự bùng nổ nhanh chóng của nghề này là hệ quả tất yếu của những chương trình đầu tư của Nhà nước và sự thành công của ngư dân khi khai thác nguồn lợi cá nổi xa bờ (Đào Mạnh Sơn, 2005). Các tỉnh miền Trung Việt Nam như Khánh Hoà, Phú Yên, Bình Định... là những tỉnh có nghề câu vàng phát triển. Từ chỗ quy mô khai thác nhỏ, chỉ sử dụng từ 300 - 600 lưỡi câu/vàng câu và thu câu bằng tay, đến nay nghề câu vàng ở các tỉnh trên đã phát triển khá hoàn thiện với vàng câu có từ 1000 - 1500 lưỡi câu và thu câu bằng máy tời (Đào Mạnh Sơn, 2002). Các loại tàu cỡ lớn cũng được đưa vào sử dụng để có những chuyến biển vươn khơi dài ngày.

Đối tượng chính của nghề câu vàng là các loài cá nổi lớn có giá trị kinh tế cao và được thị trường ưa chuộng như cá ngừ vây vàng, cá ngừ mắt to, cá cờ kiếm...(Đào Mạnh Sơn, 2002). Ngoài ra, một phần sản lượng không nhỏ là các đối tượng khai thác khác ít giá 
trị kinh tế hoặc bị bỏ đi như các loại cá hố ma, cá hố cờ, cá đỏ... và đặc biệt việc các loài thú biển, rùa biển bị mắc câu không chủ ý.

Đã có những biện pháp khác nhau nhằm bảo vệ nguồn lợi, bảo vệ các loài thủy sinh vật quý hiếm được các tổ chức hoạt động về lĩnh vực bảo vệ thiên nhiên đưa ra nhằm giảm thiểu tối đa ảnh hưởng của hoạt động khai thác tới các đối tượng như thú biển, rùa biển, chim biển. Trong đó, việc sử dụng lưỡi câu vòng (circle hook) thay thế cho lưỡi câu thường (J-hook) đã và đang được thử nghiệm để đánh giá tính chọn lọc của ngư cụ nhằm giảm thiểu việc đánh bắt không chủ ý. Các thí nghiệm đánh giá hiệu quả khai thác của lưỡi câu vòng so với lưỡi câu thường đã được thực hiện và đã đạt được những hiệu quả nhất định (Bacheler \& Buckel, 2004; Kerstetter \& Graves, 2006; Kerstetter et al., 2007; Read, 2007). Với sự hỗ trợ của Quỹ Quốc tế Bảo vệ Thiên nhiên (WWF), thí nghiệm đánh giá hiệu quả khai thác của lưỡi câu vòng với mục đích đạt năng suất khai thác cao và giảm tỉ lệ đánh bắt không chủ ý đối với rùa biển và thú biển bước đầu triển khai ở Việt Nam. Các kết quả nghiên cứu là cơ sở khoa học cho việc thay thế lưỡi câu thường bằng lưỡi câu vòng đối với nghề câu vàng khai thác nguồn lợi cá nổi lớn.

\section{TÀI LIỆU VÀ PHƯƠNG PHÁP NGHIÊN CỨU}

\section{Phương pháp thu số liệu}

\subsection{Bố trí thí nghiệm}

Mục đích chính của việc thử nghiệm lưỡi câu vòng thay thế lưỡi câu thường để đánh bắt cá nổi xa bờ là so sánh thành phần sản lượng, năng suất đánh bắt và tỷ lệ mắc câu của một số loài rùa biển, thú biển giữa lưỡi câu vòng và lưỡi câu thường.

Các chuyến thử nghiệm khả năng đánh bắt của lưỡi câu vòng được thực hiện trên các tàu câu vàng của ngư dân các tỉnh Bình Định, Phú Yên, Khánh Hòa, với 14 chuyến biển đã được thực hiện trong năm 2 năm 2009 và 2010.

Vàng câu được bố trí sử dụng đồng thời cả lưỡi câu vòng và lưỡi câu thường với tỉ lệ dự kiến là 50:50. Ngư trường khai thác thử nghiệm thuộc vùng biển xa bờ miền Trung và Đông Nam bộ, tại các khu vực khai thác truyền thống của ngư dân. Thông thường, các tàu thả câu vào buổi sáng và bắt đầu thu câu vào khoảng thời gian từ $19-21 \mathrm{~h}$.

\subsection{Phương pháp thu mẫu}

Sản lượng của từng mẻ câu được phân tích đến loài hoặc nhóm loài theo từng loại lưỡi câu, gồm cân khối lượng, đếm số cá thể bắt gặp và ghi chép một số thông số sinh học cơ bản theo hướng dẫn của Sparre \& Venema (1995). 
Đối với các mẻ câu bắt được rùa biển hoặc thú biển, tiến hành các thao tác xử lý an toàn và thả chúng trở lại biển. Thông tin về thời gian, địa điểm rùa biển/thú biển mắc câu và thao tác gỡ câu cứu hộ rùa biển/thú biển cũng như tình trạng của chúng được ghi chép, mô tả cụ thể. Đối với những cá thể đã chết, tiến hành gỡ câu và ghi chép lại các thông tin thu được về chiều dài, khối lượng, thời gian và địa điểm bị mắc câu.

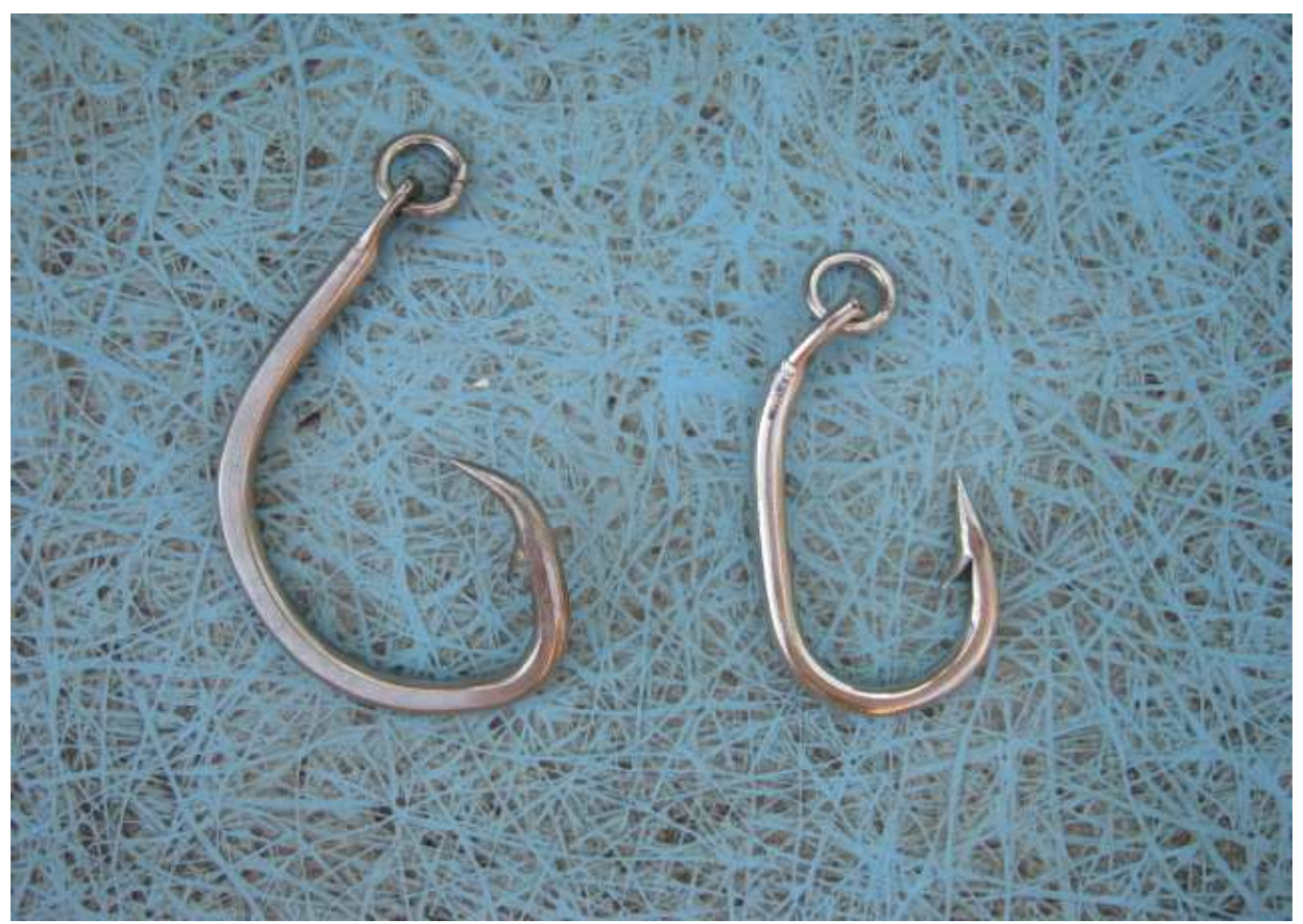

Hình 1: Lưỡi câu vòng (bên trái) và lưỡi câu thường (bên phải) sử dụng trong thí nghiệm

\section{Phương pháp phân tích số liệu}

- Thành phần sản lượng được phân tích riêng rẽ cho từng loại lưỡi câu theo phương pháp thống kê thông thường.

- Năng suất khai thác (CPUE) của nghề câu vàng được mô tả thông qua chỉ số $\mathrm{kg} / 100$ lưỡi câu và được tính theo công thức (Sparre \& Venema, 1995): CPUE $=\frac{C_{i}}{N_{i}} * 100$, trong đó: $\mathrm{C}_{\mathrm{i}}$ là sản lượng $(\mathrm{kg})$ của loại lưỡi câu $i, \mathrm{~N}_{\mathrm{i}}$ là tổng số lưỡi câu của loại lưỡi câu đó.

- Sử dụng t-Test: Paired Two Sample for Means để so sánh năng suất khai thác giữa lưỡi câu thường và lưỡi câu vòng. Phần mềm thống kê Statistica 7.0 (StatSoft, 2004) được sử dụng để phân tích thống kê năng suất khai thác trung bình của từng loại lưỡi câu. 


\section{KẾT QUẢ NGHIÊN CÚU}

\section{Thành phần loài}

Tổng số 14 chuyến biển với 233 mẻ câu đã được thực hiện với các quan sát viên trên các tàu câu vàng. Trong đó, đã sử dụng 223.910 lượt lưỡi câu, có 177.128 lượt lưỡi câu thường (chiếm 79\%) và 46.782 lưỡi câu vòng (chiếm 21\%). Trung bình mỗi mẻ thả 961 lưỡi câu. Trong tổng số 233 mẻ câu đã thả, có 71 mẻ câu không sử dụng lưỡi câu vòng (chiếm 30\%). Lưỡi câu thường $(\mathrm{J})$ được sử dụng trong tất cả các mẻ câu.

Qua 233 mẻ câu, đã bắt được 5.031 cá thể thuộc 20 họ khác nhau, trong đó, đã xác định được 41 loài, còn lại 11 nhóm cá thể chưa xác định tới loài. Trong tổng số 41 loài xác định được, có 4 loài rùa thuộc 2 họ là Demochelyidae và Cheloniidae, số còn lại là các họ cá. Thú biển không bị vướng câu trong các chuyến thử nghiệm.

Họ cá Thu ngừ (Scombridae) và họ cá cờ (Istiophoridae) có số loài bị bắt nhiều nhất trong sản lượng khai thác của nghề câu vàng (5/6 loài đã được xác định, chiếm $12 \%$ tổng số loài bắt gặp), tiếp theo là các họ cá Nhám (Carcharhinidae) và họ cá đuối (Dasyatidae) với tỉ lệ lần lượt là $12 \%, 9 \%$ tổng số loài xác định.

Loài có tần suất bắt gặp nhiều nhất là Alepisaurus ferox (79\%), tiếp theo là 2 loài cá ngừ kinh tế Thunnus obesus và Thunnus albacares (59\% và 50\%). Các loài Carcharhinus falciformis, Eretmochelys imbricata, Dasyatis zugei, Dermochelys coriacea, Ruvettus pretiosus, Tetrapturus audax, Isurus oxyrinchus chỉ bắt gặp duy nhất 1 cá thể trong tổng số 14 chuyến khảo sát.

Trong tổng số 5.031 cá thể bắt gặp, có 809 cá thể bắt gặp ở lưỡi câu vòng (chiếm $16 \%$ ) và 4.222 cá thể bắt gặp bởi lưỡi câu thường (chiếm $84 \%$ ). Đối với lưỡi câu vòng, 2 loài bắt gặp nhiều nhất là Alepisaurus ferox (78\%) và Gempylus serpens (10\%). Trong khi đó, ở lưỡi câu thường, loài Alepisaurus ferox bắt gặp nhiều nhất (47\%), tiếp đến là loài Gempylus serpens (23\%). Như vậy, trong tổng số các cá thể bắt gặp trong 233 mẻ câu thì các loài cá ít giá trị kinh tế là Alepisaurus ferox và Gempylus serpens lại là những đối tượng chiếm ưu thế về số lượng, trong khi các loài cá là đối tượng chính của nghề câu là Thunnus obesus và Thunnus albacares lại bắt gặp ít hơn.

\section{Sản lượng và năng suất khai thác}

Tổng số 233 mẻ câu, đã đánh bắt được khoảng $31.400 \mathrm{~kg}$ các loại, trong đó lưỡi câu vòng đạt $17 \%$ và lưỡi câu thường đạt $83 \%$ về khối lượng. Năng suất trung bình của cả các mẻ câu đạt 18,4 kg/100 lưỡi câu đối với lưỡi câu vòng và $15,9 \mathrm{~kg} / 100$ lưỡi câu đối với lưỡi câu thường (bảng 1 ). Tuy nhiên, biến động năng suất khai thác của lưỡi câu vòng so với lưỡi câu thường là rất lớn (hình 2 ). 
Bảng 1: Sản lượng và năng suất khai thác trung bình của 2 loại lưỡi câu vòng và thường

\begin{tabular}{|l|r|r|r|r|r|}
\hline Loại lưỡi câu & Số mẫu & $\begin{array}{c}\text { CPUE } \\
\text { (kg/100 lưỡi } \\
\text { câu) }\end{array}$ & Độ lệch chuẩn & $\begin{array}{l}\text { Tổng sản lượng } \\
\text { (kg) }\end{array}$ & $\begin{array}{l}\text { Tỉ lệ } \\
(\%)\end{array}$ \\
\hline Lưỡi câu vòng & 162 & 18,4 & 89,1 & 5.397 & 17 \\
\hline Lưỡi câu thường & 233 & 15,9 & 14,2 & 26.004 & 83 \\
\hline
\end{tabular}

Kết quả so sánh năng suất khai thác trung bình (t-Test) của của lưỡi câu vòng và lưỡi câu thường cho thấy không có sự khác biệt về năng suất khai thác giữa hai loại lưỡi câu (p>0,05). Như vậy, kết quả nghiên cứu cho thấy, việc sử dụng lưỡi câu vòng thay thế lưỡi câu thường không gây lo ngại tới năng suất khai thác của nghề câu vàng.

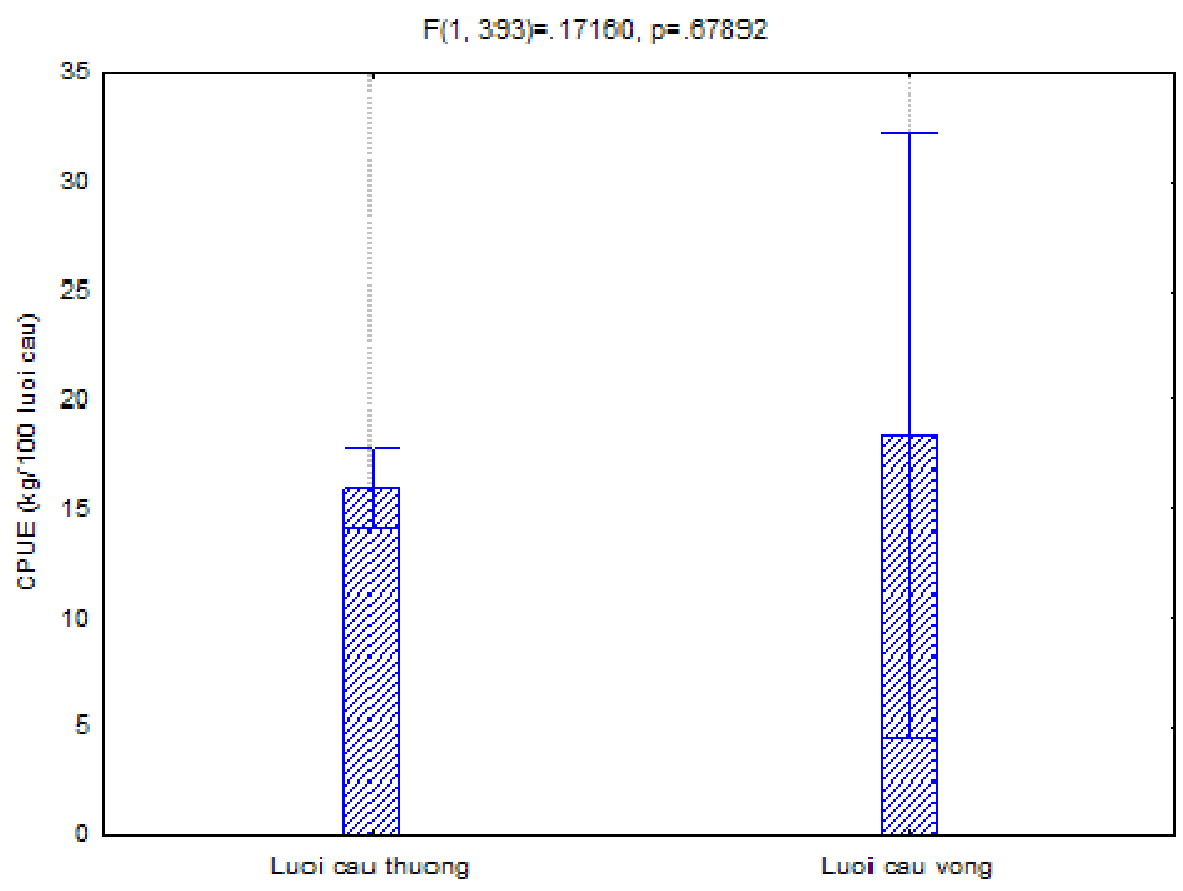

Hình 2: Năng suất khai thác cá nổi lớn trung bình (CPUE, kg/100 lưỡi câu) và khoảng tin cậy $95 \%$ của năng suất khai thác trung bình đối với từng loại lưỡi câu

Năng suất khai thác $(\mathrm{kg} / 100$ lưỡi câu) của các loài theo từng loại lưỡi câu được trình bày ở bảng 2 . Kết quả phân tích cho thấy có sự khác nhau về năng suất khai thác giữa lưỡi câu vòng và lưỡi câu thường đối với từng loài. Đối với lưỡi câu vòng, loài Thunnus albacares là loài có năng suất khai thác cao nhất đạt 7,9 kg/100 lưỡi câu, tiếp theo là các 
loài Alepisaurus ferox, Makaira indica và Thunnus obesus lần lượt đạt 2,8; 1,8 và 1,3 $\mathrm{kg} / 100$ lưỡi câu. Với lưỡi câu thường, loài có năng suất khai thác cao nhất là Thunnus obesus (đạt 3,8 kg/100 lưỡi câu), tiếp theo là các loài Thunnus albacares, Alepisaurus ferox và Makaira indica lần lượt đạt 3,6; 2,3 và $0,8 \mathrm{~kg} / 100$ lưỡi câu. Như vậy có thể thấy rằng năng suất cao ở cả lưỡi câu vòng và lưỡi câu thường vẫn tập trung vào nhóm cá có giá trị kinh tế cao là cá ngừ và cá cờ.

Bảng 2: Tỉ lệ sản lượng (SL, \%) và năng suất khai thác (CPUE, kg/100 lưỡi câu) của các loài bắt gặp ở từng loại lưỡi câu

\begin{tabular}{|l|c|c|c|c|}
\hline \multirow{2}{*}{ Tên loài } & \multicolumn{2}{|c|}{ Lươi câu vòng } & \multicolumn{2}{c|}{ Lưỡi câu thường } \\
\cline { 2 - 5 } & \% SL & CPUE & \% SL & CPUE \\
\hline Acanthocybium solandri & 0,16 & 0,03 & 0,50 & 0,08 \\
\hline Aetomylaeus nichofii & 0,00 & 0,00 & 0,05 & 0,01 \\
\hline Alepisaurus ferox & 15,71 & 2,89 & 14,81 & 2,36 \\
\hline Alopias pelagicus & 0,00 & 0,00 & 1,91 & 0,30 \\
\hline Alopias superciliosus & 1,59 & 0,29 & 0,18 & 0,03 \\
\hline Brama orcini & 0,00 & 0,00 & 1,55 & 0,25 \\
\hline Brama sp. & 0,00 & 0,00 & 0,00 & 0,00 \\
\hline Carcharhinidae & 0,00 & 0,00 & 2,29 & 0,36 \\
\hline Carcharhinus falciformis & 1,49 & 0,27 & 0,00 & 0,00 \\
\hline Carcharhinus obscurus & 1,04 & 0,19 & 0,92 & 0,15 \\
\hline Carcharhinus sp. & 4,55 & 0,84 & 0,10 & 0,02 \\
\hline Chelonia mydas & 0,00 & 0,00 & 0,03 & 0,01 \\
\hline Coryphaena hippurus & 0,33 & 0,06 & 0,56 & 0,09 \\
\hline Dasyatis kuhlii & 0,07 & 0,01 & 0,10 & 0,02 \\
\hline Dasyatis sp. & 2,15 & 0,40 & 1,26 & 0,20 \\
\hline Dasyatis zugei & 0,00 & 0,00 & 0,16 & 0,03 \\
\hline Dermochelys coriacea & 0,00 & 0,00 & 0,18 & 0,03 \\
\hline Eretmochelis imbricata & 0,00 & 0,00 & 0,03 & 0,01 \\
\hline Galeocerdo cuvier & 0,81 & 0,15 & 0,17 & 0,03 \\
\hline Gempylus serpens & 1,38 & 0,25 & 5,04 & 0,80 \\
\hline Istiophorus platypterus & 2,19 & 0,40 & 2,04 & 0,32 \\
\hline Istiophorus spp. & 0,00 & 0,00 & 1,45 & 0,23 \\
\hline Isurus oxyrinchus & 0,00 & 0,00 & 0,18 & 0,03 \\
\hline
\end{tabular}




\begin{tabular}{|c|c|c|c|c|}
\hline \multirow{2}{*}{ Tên loài } & \multicolumn{2}{|c|}{ Lưỡi câu vòng } & \multicolumn{2}{|c|}{ Lưỡi câu thường } \\
\hline & $\% \mathrm{SL}$ & CPUE & $\% \mathrm{SL}$ & CPUE \\
\hline Katsuwonus pelamis & 0,00 & 0,00 & 0,14 & 0,02 \\
\hline Lampris guttatus & 0,00 & 0,00 & 0,54 & 0,09 \\
\hline Lampris sp. & 0,00 & 0,00 & 0,06 & 0,01 \\
\hline Lepidochelys olivacea & 0,06 & 0,01 & 0,27 & 0,04 \\
\hline Lepidocybium flavobrunneum & 0,35 & 0,06 & 0,71 & 0,11 \\
\hline Makaira indica & 9,80 & 1,80 & 5,03 & 0,80 \\
\hline Makaira mazara & 0,00 & 0,00 & 1,24 & 0,20 \\
\hline Makaira nigricans & 1,54 & 0,28 & 0,70 & 0,11 \\
\hline Mene maculata & 0,00 & 0,00 & 0,04 & 0,01 \\
\hline Mobula spp. & 0,93 & 0,17 & 0,00 & 0,00 \\
\hline Prionace glauca & 1,93 & 0,35 & 1,17 & 0,19 \\
\hline Pseudocarcharias kamoharai & 0,00 & 0,00 & 0,58 & 0,09 \\
\hline Pteroplatytrygon violacea & 0,00 & 0,00 & 0,06 & 0,01 \\
\hline Ruvettus pretiosus & 0,02 & 0,00 & 0,00 & 0,00 \\
\hline Sargocentron rubrum & 0,02 & 0,00 & 0,13 & 0,02 \\
\hline Scomberomorus spp. & 0,00 & 0,00 & 0,20 & 0,03 \\
\hline Sphyraena barracuda & 0,00 & 0,00 & 0,13 & 0,02 \\
\hline Sphyrna lewini & 0,50 & 0,09 & 1,63 & 0,26 \\
\hline Taractes sp. & 0,34 & 0,06 & 0,03 & 0,01 \\
\hline Taractichthys longipinnis & 0,06 & 0,01 & 0,17 & 0,03 \\
\hline Taractichthys steindachneri & 0,00 & 0,00 & 0,02 & 0,00 \\
\hline Tetrapturus audax & 0,00 & 0,00 & 0,04 & 0,01 \\
\hline Thunnus alalunga & 0,68 & 0,12 & 0,92 & 0,15 \\
\hline Thunnus albacares & 43,14 & 7,94 & 23,08 & 3,68 \\
\hline Thunnus obesus & 7,12 & 1,31 & 24,12 & 3,84 \\
\hline Trichiurus lepturus & 0,00 & 0,00 & 3,06 & 0,49 \\
\hline Trichiurus sp. & 0,00 & 0,00 & 0,02 & 0,00 \\
\hline Xiphias gladius & 2,04 & 0,38 & 2,38 & 0,38 \\
\hline Cá khác & 0,00 & 0,00 & 0,01 & 0,00 \\
\hline Tổng & 100,00 & 18,40 & 100,00 & 15,94 \\
\hline
\end{tabular}

Ghi chú: 0,00 là nhỏ hơn 0,001 
Cá ngừ mắt to (Thunnus obesus) và loài cá ngừ vây vàng (Thunnus albacares) là 2 loài quan trọng nhất và có giá trị nhất trong các chuyến biển của ngư dân. Qua 14 chuyến thử nghiệm, đã bắt được 380 cá thể của 2 loài cá này với tổng sản lượng đạt khoảng $13.240 \mathrm{~kg}$ (chiếm khoảng $42 \%$ tổng sản lượng khai thác). Trung bình, mỗi cá thể có khối lượng khoảng $35 \mathrm{~kg}$. Trong 380 cá thể được cân khối lượng và đo chiều dài, có 249 cá thể có khối lượng $\geq 30 \mathrm{~kg}$ (chiếm khoảng $66 \%$ ), đạt tiêu chuẩn là cá xuất khẩu loại 1 . Điều này cho thấy, cá ngừ đánh bắt được có chất lượng tốt chiếm tỷ lệ cao trong sản lượng cá ngừ khai thác.

Trong tổng số 162 mẻ câu sử dụng đồng thời 2 loại lưỡi câu, có 124 mẻ bắt gặp cá ngừ vây vàng hoặc mắt to. Năng suất khai thác trung bình của 2 loài cá này ở lưỡi câu vòng cao hơn ở lưỡi câu thường, đạt $9,25 \mathrm{~kg}$ ở lưỡi câu vòng và $7,53 \mathrm{~kg} / 100$ lưỡi câu ở lưỡi câu thường. Kết quả so sánh trung bình bằng $\mathrm{t}$-Test cho thấy không có sự khác nhau về năng suất khai thác 2 loài cá này ở lưỡi câu vòng và lưỡi câu thường $(p>0,05)$ nếu gộp cả cá ngừ vây vàng và cá ngừ mắt to thành một nhóm. Nhưng nếu tách riêng sản lượng từng loại cá ngừ để so sánh thì tính chọn lọc ngư cụ của từng loại lưỡi câu đối với các loài khác nhau thể hiện khá rõ. Năng suất khai thác cá ngừ vây vàng bằng lưỡi câu thường thấp hơn so với khai thác bằng lưỡi câu vòng, nhưng đối với cá ngừ mắt to thì hiệu quả khai thác ngược lại. Sử dụng lưỡi câu thường cho năng suất khai thác cá ngừ mắt to cao hơn so với lưỡi câu vòng. Kết quả so sánh năng suất khai thác của từng loại lưỡi câu đối với hai loài cá ngừ cho thấy, sự khác biệt về năng xuất khai thác có ý nghĩa thống kê với độ tin cậy $95 \%$ ( $\mathrm{p}<0,05)$. Như vậy, nếu xét hiệu quả đánh bắt chung cho nhóm cá ngừ Đại dương thì việc sử dụng lưỡi câu vòng thay thế cho lưỡi câu thường không gây lo ngại về năng suất khai thác đối với hai đối tượng chính của nghề câu.

\section{Thông tin về rùa biển, thú biển bắt gặp trong các chuyến điều tra}

Trong 14 chuyến thử nghiệm lưỡi câu vòng đã bắt gặp 8 cá thể rùa biển thuộc 4 loài là Lepidochelys olivacea (4 cá thể), Dermochelys coriacea (1 cá thể) Eretmochelis imbricata ( 2 cá thể) và Chelonia mydas ( 1 cá thể). Trong đó có 2 cá thể đã bị chết trước khi được phát hiện, còn lại 6 cá thể đã được các quan sát viên và các thuỷ thủ trên tàu gỡ câu, cứu sống và thả trở lại biển. Trong 8 cá thể rùa biển đã bắt gặp, có 7 cá thể bị bắt bởi lưỡi câu thường (chiếm $88 \%$ ) và $1(12 \%)$ cá thể bị bắt bởi lưỡi câu vòng. Như vậy có thể thấy tỉ lệ đánh bắt không chủ ý đối với rùa biển của lưỡi câu vòng thấp hơn so với lưỡi câu thường. Các thông tin cơ bản của 8 cá thể rùa biển được trình bày ở bảng 3 . 
Bảng 3: Thông tin về rùa biển bắt gặp trong các chuyến điều tra thử nghiệm

\begin{tabular}{|c|c|c|c|c|c|c|c|c|c|c|c|}
\hline STT & $\begin{array}{c}\text { Mã } \\
\text { chuyến }\end{array}$ & Mẻ số & Tên loài & $\begin{array}{c}\text { Khối } \\
\text { lượng } \\
(\mathrm{kg})\end{array}$ & $\begin{array}{c}\text { Dài mai } \\
(\mathrm{cm})\end{array}$ & $\begin{array}{l}\text { Rộng } \\
\text { mai } \\
\text { (cm) }\end{array}$ & $\begin{array}{l}\text { Lưỡi } \\
\text { câu }\end{array}$ & $\begin{array}{l}\text { Vị trí } \\
\text { mắc câu }\end{array}$ & $\begin{array}{c}\text { Tình } \\
\text { trạng } \\
\text { lúc } \\
\text { gặp }\end{array}$ & $\begin{array}{c}\text { Tình } \\
\text { trạng } \\
\text { lúc thả }\end{array}$ & $\begin{array}{l}\text { Ghi } \\
\text { chú }\end{array}$ \\
\hline 1 & 2004 & 16 & $\begin{array}{l}\text { Lepidochelys } \\
\text { olivacea }\end{array}$ & 18 & 60 & 62 & $\mathrm{~J}$ & $\begin{array}{l}\text { Sâu } \\
\text { trong cổ }\end{array}$ & Sống & Sống & \\
\hline 2 & 2008 & 9 & $\begin{array}{l}\text { Lepidochelys } \\
\text { olivacea }\end{array}$ & 22 & 50 & 40 & $\mathrm{~J}$ & Miệng & Sống & Sống & \\
\hline 3 & 2008 & 24 & $\begin{array}{l}\text { Eretmochelis } \\
\text { imbricata }\end{array}$ & 5 & 30 & 29 & $\mathrm{~J}$ & Miệng & Sống & Sống & \\
\hline 4 & 3008 & 7 & $\begin{array}{l}\text { Lepidochelys } \\
\text { olivacea }\end{array}$ & 12 & 56 & 40 & $\mathrm{~J}$ & Miệng & Chết & Chết & \\
\hline 5 & 3008 & 8 & $\begin{array}{l}\text { Lepidochelys } \\
\text { olivacea }\end{array}$ & 6 & 42 & 34 & $\mathrm{C}$ & Miệng & Chết & Chết & \\
\hline 6 & 3008 & 11 & $\begin{array}{l}\text { Dermochelys } \\
\text { coriacea }\end{array}$ & 50 & & & $\mathrm{~J}$ & $\begin{array}{l}\text { Sâu } \\
\text { trong cổ }\end{array}$ & Sống & Sống & $\begin{array}{l}\text { Cắt } \\
\text { dây } \\
\text { câu }\end{array}$ \\
\hline 7 & 3003 & 17 & $\begin{array}{l}\text { Chelonia } \\
\text { mydas }\end{array}$ & 5 & 28,5 & 26 & $\mathrm{~J}$ & Miệng & Sống & Sống & \\
\hline 8 & 3003 & 18 & $\begin{array}{l}\text { Eretmochelis } \\
\text { imbricata }\end{array}$ & 2,5 & 18,5 & 20,5 & $\mathrm{~J}$ & $\begin{array}{l}\text { Bên } \\
\text { ngoài }\end{array}$ & Sống & Sống & \\
\hline
\end{tabular}

\section{MỘT SỐ NHẬN XÉT VÀ KHUYẾN NGH!̣}

\section{Một số nhận xét}

Thành phần loài hải sản khai thác bằng nghề câu vàng khá nghèo nàn. Kết quả quan sát từ 14 chuyến biển chỉ bắt gặp 52 loài/nhóm loài thuộc 20 họ khác nhau.

Năng suất khai thác của các chuyến thử nghiệm khá cao, trung bình đạt khoảng 18,4 và $15,9 \mathrm{~kg} / 100$ lưỡi câu đối với lưỡi câu vòng và lưỡi câu thường. Năng suất khai thác của lưỡi câu vòng và lưỡi câu thường không khác nhau.

Tính lựa chọn ngư cụ của lưỡi câu vòng và lưỡi câu thường đối với các loài cá nổi lớn khác nhau. Năng suất khai thác cá ngừ vây vàng và các loài cá nhám bằng lưỡi câu vòng cao hơn so với lưỡi câu thường. Ngược lại, sử dụng lưỡi câu thường khai thác cá ngừ mắt to cho năng suất cao hơn. 
Đã bắt gặp 8 cá thể rùa biển, trong đó 7 cá thể bị mắc lưỡi câu thường và 1 cá thể bị mắc lưỡi câu vòng. Như vậy, bước đầu đã xác định được tính lựa chọn ngư cụ của lưỡi câu vòng có thể đã hạn chế khả năng đánh bắt không chủ ý đối với rùa biển.

\section{Khuyến nghị}

- Cần có thêm các nghiên cứu thử nghiệm để đánh giá hiệu quả đánh bắt của lưỡi câu vòng và lưỡi câu thường với mục đích tăng năng suất khai thác, hiệu quả kinh tế và giảm thiểu việc đánh bắt rùa biển/thú biển không chủ ý.

- Cần tuyên truyền sâu rộng đến các chủ phương tiện khai thác, thuyền trưởng và ngư dân về việc sẽ sử dụng lưỡi câu vòng để khai thác nguồn lợi với mục đích bảo vệ, bảo tồn các loài thủy sinh vật quý hiếm, trong đó có rùa biển và thú biển.

- Các quan sát viên trên tàu cần được đào tạo, tập huấn sâu hơn toàn diện hơn, đặc biệt là kiến thức về ngư loại học và cấp cứu rùa biển, thú biển.

\section{TÀI LIỆU THAM KHẢO}

1. Đào Mạnh Sơn, 2002. Báo cáo tổng kết đề tài "Nghiên cứu, thăm dò nguồn lợi hải sản và lựa chọn công nghệ khai thác phù hợp phục vụ phát triển nghề cá xa bờ Việt Nam". Lưu trữ tại thư viện Viện Nghiên cứu Hải sản.

2. Đào Mạnh Sơn, 2005. Nghiên cứu trữ lượng và khả năng khai thác cá nổi lớn ở vùng biển xa bờ miền Trung và Đông Nam bộ. Báo cáo tổng kết đề tài cấp bộ. Viện Nghiên cứu Hải sản, Hải Phòng.

3. Nathan M. Bacheler \& Buckel Jeffrey A., 2004. Does hook type influence the catch rate, size, and injury of grouper in a North Carolina commercial fishery? Fisheries Research 69: 303-311.

4. D.W. Kerstetter \& Graves J.E., 2006. Effects of circle versus J-style hooks on target and non-target species in a pelagic longline fishery. Fisheries Research 80: 239-250.

5. D.W. Kerstetter, Pacheco J.C., Hazin F.H., Travassos P.E. \& Graves J.E., 2007. Preliminary results of circle and $j$-style hook comparisons in the Brazilian pelagic longline fishery. Col. Vol. Sci. Pap. ICCAT 60(6): 2140-2147.

6. Andrew J. Read, 2007. Do circle hooks reduce the mortality of sea turtles in pelagic longlines? A review of recent experiments. Biological conservation 135: 155-169. 
7. Per Sparre \& Venema Siebren C., 1995. Introduction to tropial fish stock assessment, part I - manual, 306/1 Rev 1. FAO Rome

8. Inc. StatSoft, 2004. STATISTICA (data analysis software system), version 7.

\title{
PRELIMINARY COMPARISONS ON EFFECTIVE USE OF CIRCLE AND J-STYLE HOOKS IN THE VIETNAMESE PELAGIC LONGLINE FISHERY
}

\author{
VU VIET HA, NGUYEN VAN HAI
}

\begin{abstract}
Summary: In 2009 and 2010, a total of 14 experiment fishing trips using both circle and J-style hooks on the longline fishing vessel was conducted off the coast of Central and South-eastern waters of Vietnam. The purpose of experiments is to estimate the catching efficiency of the circle hook and the j-hook, also considering the reduction and outreach of sea turtle by-catch. Results showed that the catch rate of the circle hook and j-hook is no significant different but the catch composition of circle hook differed in comparison to that of j-hook. Circle hook is high effective in catching yellow fin tuna, sharks and swordfish while the j-hook targeted highly in big eye tuna. Results also indicated that the reduction and outreach of sea turtle is higher with circle hook.
\end{abstract}

Keywords: circle hook, j-hook, pelagic, catch rate, species composition.

Ngày nhận bài: $25-8$ - 2010

Người nhận xét: PGS. TS. Hồ Thanh Hải 